\title{
Government Policy to Encourage Customers to Support Development of Renewable Energy in Indonesia - A Proposal
}

\author{
Atmonobudi Soebagio, Senior Member IEEE and Bambang Widodo
}

\begin{abstract}
Indonesia is blessed with abundant renewable energy resources. Nevertheless, they have only been used to cover about $5 \%$ of the total national energy demand. To optimize their utilization, the government has to make and implement a policy that will encourage PLN costumers to help increase their on-grid power supply capacity. This policy will provide benefits for islands that are already equipped with PLN power grids. This paper uses Solar Power Plants and household costumers as models to calculate potential on-grid power increase which can be contributed by PLN costumers. A two-way power meter is used to replace the currently used one. This model will be applied to the conventional grid to demonstrate the compatibility that show how it is applicable even without upgrading the conventional grid to become smart grid system. The result shows that customers can participate significantly through the flow of their excess energy to grid
\end{abstract}

Index Terms-Fossil energy, fossil fuel, coal, oil, gas, renewable energy, Solar PV Plant, sustainable development, power consumers, PLN, two-way kWh meter, smart grid.

\section{INTRODUCTION}

A switch to a non-fossil energy system has become unavoidable if we are to ensure a more secured, reliable and sustainable future. However, this requires a more significant contribution from renewable energy resources such as solar and wind, and identification of challenges in terms of flexibility, storing and transmission of energy. Customers play an important role in making this transition possible: their flexibility is needed to accommodate the fluctuating generation of power and peak time loads. Customers need to be flexible when using energy and selecting modes of technology that can rely more on renewable energy [1]. Meanwhile, the plan to build a nuclear fission power plant in Indonesia should be cancelled, as it poses many risks and not so economically feasible [5].

Manuscript received April 1, 2017; revised April 10, April 13, April 19, and April 23, 2017; accepted April 28, 2017.

A. Soebagio is with the Department of Electrical Engineering, Faculty of Engineering, The Christian University of Indonesia, Jakarta (email: atmonobudi@uki.ac.id)

B. Widodo is with the Department of Electrical Engineering, Faculty of Engineering, The Christian University of Indonesia, Jakarta (email: bambang.widodo@uki.ac.id)
A break through in the form of a government policy is needed to encourage customers to contribute by using renewable energy which will also provide them with benefits.

Indonesia is blessed with huge potentials of renewable energy, in particular geothermal, hydropower, wind power, solar photovoltaic (PV) and biomass energy. However, despite the potentials, Indonesia is also faced with many energy-related challenges as it covers a huge geographical territory, comprising of 17,000 islands, 6,000 of which are inhabited, with highly diverse population density and economic activities.

Reserve of fossil energy is depleting, while in the last few years coal export stood only at $80 \%$ of its total annual production. Electricity supply is still limited, barely accessible to those living in underdeveloped, remote areas, and those on the border areas. Power generation to supply these areas will rely on renewable resources, but this requires funding and knowledge of technology.

Electricity consumption in the year 2050 has been predicted to jump up to 6.1 up to 7.5 times of that in the year 2015. Electricity subsidies have been reduced as 12 categories of power consumers are no longer subsidized, pursuant to the Regulation of Minister of Energy and Mineral Resources Number 31/2014. These 12 categories of consumers include household consumers (400 VA up to $\geq 6.600 \mathrm{VA}$ ), business consumers $(\geq 6.600 \mathrm{VA})$, industrial consumers $(\geq 200 \mathrm{kVA})$, government offices ( $\geq 6.600 \mathrm{VA}$ ), low voltage public lightings and special service. The subsidies cut for electricity and fuel has led to that for energy, from 315 trillion Rupiah in 2014 to be 119 trillion Rupiah in 2015, the difference of which was used to build infrastructure and conduct social development.

The target to increase power by 35,000 megawatt (MW) in 2019 is relatively hard to meet since the coal reserve necessary to fire power plants has been depleting continuously. As contained in 2016-2025 RUPTL of PLN, the capacity of installed plants, both owned by PLN and IPPs in Indonesia up to 2015 constituted $48,065 \mathrm{MW}, 33,824 \mathrm{MW}$ of which was in Java-Bali system, while 10,091 MW was distributed in electricity systems in Sumatra, and the remaining 4,150 MW in Eastern Indonesia. If the capacity of the rented plants which amounted to 3,703 MW is counted, the whole capacity reached 51,348 MW. PLN's coal-fired plants supplied most of the power supply $(48,9 \%)$.

The huge amount of power generation by coal-fired plants compared to that generated by other types of plants is actually quite problematic as this contradicts with the policy to promote energy diversification which has been perceived as a way to 
sustain the national energy security as well as a policy to conserve energy.

Government Regulation Number 79/2014 concerning the National Energy Policy sets a target for renewable energy utilization to make up $23 \%$ of the total energy mix in in 2025 , and $31 \%$ of the total energy mix in 2050. Indonesian National Energy Council predicted that coal will be completely depleted in 2025, while fossil fuel supply (69\%) will completely dry out in 2050. Consequently, all fossil energy (coal, oil and gas) will have to be imported.

In this paper, the analysis will focus on household customers and only the electricity data from Java-Bali power grid is used, as this grid had the biggest amount of power. Renewable energy type covered herein is limited to solar power only as this type of power is available in different packages and installation of panels was quick and easy. In addition, as a country, utilization of this type of energy will provide the most favorable competitive advantage for a country which is located on equator, like Indonesia.

\section{Potency Of Household Customers}

Under Regulation of Minister of Energy and Mineral Resources No. 31/2014 [4], electricity consumers are categorized as follows (1) Household, (2) Commercial, (3) Public and (4) Industry, as shown below in Fig.1 and Fig.2.

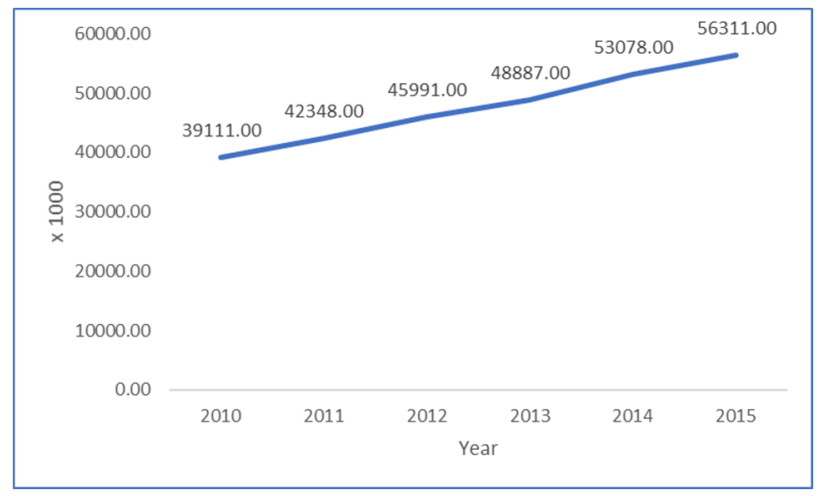

Fig.1. Increasing number of household customers from 2010 up to 2015. [3]

Fig.2 shows the number of commercial, public, and industrial customers in Indonesia respectively. Number of industrial customers is the lowest, but larger than public customers in term of MVA loads.

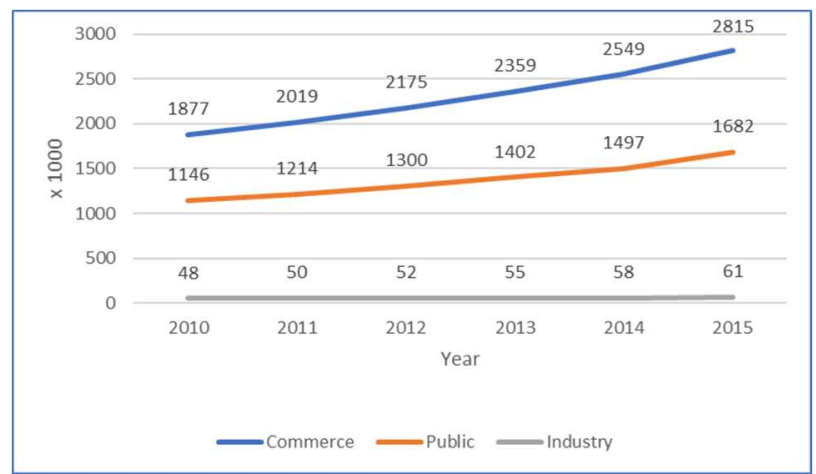

Fig.2. Increasing number of commercial, public, and industrial customers from 2010 up to 2015. [4]
Fig.3 shows classification of power consumption based on types of household customers based on Indonesia (total), JawaBali and Sumatera regions repectively. This paper only looked into household customers as model of participation as this type of customers constitutes the majority of customers.

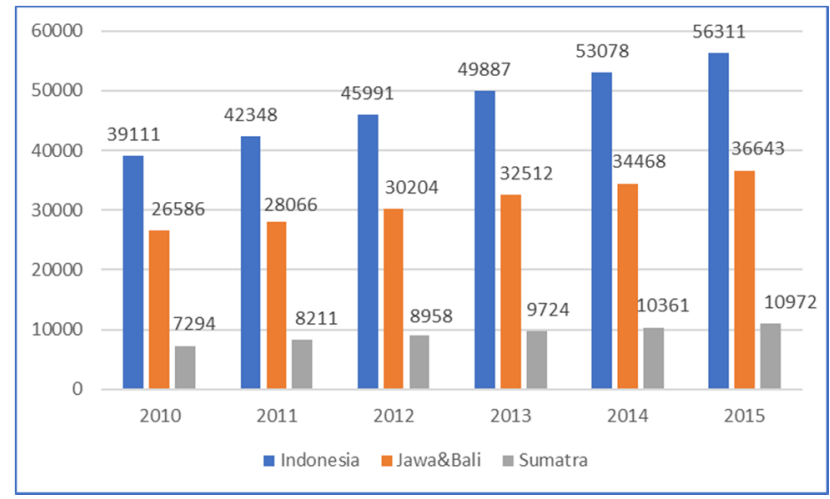

Fig.3. Number of Household Customers based upon Regions in Indonesia. [5]

This calculation is based on the assumed participation of household costumers who own solar PV plant, which is the lowest tariff compared to that of business and industrial customers. Assumed power contribution by customers owning solar PV plants can be seen in Table I.

TABLE I. CATEGORY OF HOUSEHOLD, BUSINESS, AND INDUSTRIES CUSTOMERS

\begin{tabular}{|c|c|c|c|}
\hline No. & $\begin{array}{l}\text { Category of } \\
\text { Customers }\end{array}$ & Power & Code \\
\hline \multicolumn{4}{|c|}{ Household } \\
\hline 1 & Small & $450 \mathrm{VA} ; 900 \mathrm{VA} ; 1,300 \mathrm{VA}$ & $\mathrm{R}-1 / \mathrm{TR}$ \\
\hline 2 & Medium & $3,500 \mathrm{VA}$ up to $5,500 \mathrm{VA}$ & $\mathrm{R}-2 / \mathrm{TR}$ \\
\hline 3 & Large & $\geq 6,600 \mathrm{VA}$ & $\mathrm{R}-3 / \mathrm{TR}$ \\
\hline \multicolumn{4}{|c|}{ Business } \\
\hline 1 & Small & $450 \mathrm{VA}$ up to $5,500 \mathrm{VA}$ & $\mathrm{B}-1 / \mathrm{TR}$ \\
\hline 2 & Medium & $6,600 \mathrm{VA}$ up to $200 \mathrm{KVA}$ & $\mathrm{B}-2 / \mathrm{TR}$ \\
\hline 3 & Large & $>200 \mathrm{KVA}$ & B-3/TR \\
\hline \multicolumn{4}{|c|}{ Industry } \\
\hline 1 & Small & $450 \mathrm{VA}$ up to $14 \mathrm{KVA}$ & $\mathrm{I}-1 / \mathrm{TR}$ \\
\hline 2 & Small to Medium & $14 \mathrm{KVA}$ up to $200 \mathrm{KVA}$ & $\mathrm{I}-2 / \mathrm{TR}$ \\
\hline 3 & Medium & $>200 \mathrm{KVA}$ & $\mathrm{I}-3 / \mathrm{TM}$ \\
\hline 4 & Large & $\geq 30,000 \mathrm{KVA}$ & $\mathrm{I}-4 / \mathrm{TT}$ \\
\hline
\end{tabular}

This is only preliminary contribution, made pursuant to the issuance of supporting government policy, and this will increase as more and more customers are aware of the benefits they can earn as customers of PLN with solar PV plants.

TABLE II. AsSUMED POWER CONTRIBUTION By CUSTOMERs OWNING SOLAR PANEL

\begin{tabular}{|c|c|c|c|c|c|}
\hline $\begin{array}{l}\text { Category } \\
\text { of } \\
\text { Customer } \\
\end{array}$ & $\begin{array}{c}\text { Power } \\
\text { (VA) }\end{array}$ & $\begin{array}{c}\text { Solar Power } \\
\text { Gen. } \\
\text { (Wp) }\end{array}$ & $\begin{array}{c}\text { Partici- } \\
\text { pation } \\
(\%)\end{array}$ & $\begin{array}{c}\text { No. of Solar } \\
\text { Panel } \\
\text { Owners } \\
\end{array}$ & $\begin{array}{l}\text { Power } \\
(\mathbf{k W p})\end{array}$ \\
\hline \multicolumn{6}{|c|}{ Household } \\
\hline Small & $\begin{array}{r}900 \\
1,300 \\
\end{array}$ & 500 & 0.1 & 5,311 & $2,655.5$ \\
\hline Medium & $\begin{array}{l}3,500 \\
\text { up to } \\
5,500 \\
\end{array}$ & 1,000 & 0.3 & 15,933 & $15,930.0$ \\
\hline Large & $\geq 6,600$ & 2,500 & 0.5 & 26,555 & $66,378.5$ \\
\hline \multicolumn{5}{|c|}{ Total Solar Power Generated by Household } & 84,976 \\
\hline
\end{tabular}


Table II is based on the assumed capacity of solar PV plants owned by customers, the volume of which is proportional to the customer's power consumption category. This calculation shows that potential power generator from solar PV plants can reach up to $84,976 \mathrm{kWp}$, or $85 \mathrm{MWp}$ when uprounded

\section{CUSTOMERS' Response TOWARD THE MARKET}

Currently, the number of customers in possession of solar PV panels has been increasing, despite the fact that it remains a small number. To further encourage the growth, a breakthrough government policy is needed to motivate other customers to own alternative power generators such as solar power plant (PLTS), biomass power plant (PLTB), and microhydro power plant (PLTMH).

Positive response will increase as price of solar PV units becomes more affordable, along with the improvement of production technology of solar PV manufacturers

Positive response will increase as price of solar PV units becomes more affordable, along with the improvement of production technology of solar PV manufacturers. According to Swanson Law, the price of solar photovoltaic modules (solar panels) tends to drop by $19-23 \%$ for every doubling of cumulative shipped volume (production) thereof [6]. Also, PV power efficiency tends to rise, which means that panel size and weight will decrease when installed on the roof.

\section{A Proposed Pro Customer Government Policy}

To help boost participation of household customers to own solar panels, government needs to pass a regulation that is in favor of the customers. Contribution by PLN customers to increase power supply can be done by:

1. Replacing their currently installed one-way KWh-meter with a two-way meter, with assistance of PLN. This meter will record both incoming and outgoing power flow.

2. To encourage customers to participate, government will promote the installation of two-way KWh meter to replace the old one, although this is not compulsory.

The procedures are as follows:

1. PLN customers in possession of solar PV plants register their solar PV to PLN and apply for a permit for interconnection to PLN grid. PLN will then send their personnel to inspect.

2. If granted, PLN will replace the old meter with a new twoway $\mathrm{kWh}$ meter.

\section{BENEFIT FOR PLN AND CUSTOMERS}

With the participation of customers whose solar panels connected to PLN grid, the following benefits can be earned by PLN and customers:

1. PLN will be supported during its peak load time. This will be very helpful, since the Java-Bali's load continuously grew at the annual average rate of 5.8\% between 2010-2015 [4].

2. Customers' electricity charges will decline as they can be set off with power supplied from customers' panels. PLN will not suffer from any reduction of revenue since the power will be utilized and paid by other, non-solar PVowner customers.

3. The plan to build new power plants to increase power supply can be temporarily suspended.

4. Costumers' participation will induce diversification of power generation from renewable energy, cutting down dependence on coal, which in turn will reduce $\mathrm{CO}_{2}$ emission. Coal-fired power plants, to compare with, emit $\mathrm{CO}_{2}$ as much as $940 \mathrm{kgCO}_{2} / \mathrm{MW}_{\mathrm{e}} \mathrm{h}$, while solar PV plants only emit $63 \mathrm{kgCO}_{2} / \mathrm{MW}_{\mathrm{e}}$.

5. The development of smart grid to replace the conventional grid will further encourage customers to possess on grid solar PVs.

6. Indonesian energy sector will become more resilient as PLN and customers jointly meet power demands through installation of solar PV panels.

On the other hand, the benefits for customers are as follows:

1. Customers can use power which exceeds their category by combining the power from PLN and from their solar PV panels.

2. Customers can send back their unused power to PLN when their load is low at home.

3. The excessive power fed into PLN system will be calculated to set off the utility charges in the following month.

If PLN upgrades their system to become smart grid, the customer participation will increase as they will be categorized as partners in power production. Customers can be household or industry.

\section{CONCLUSION}

A strong economic and legal support provided by the government in the form of a pro customer policy will significantly upscale the contribution of customers to the Indonesian power supply from renewable energy. PLN and their customers who own solar PV panel will jointly provide power that used to be solely provided by a centralized, one-way power generation system. In its place, we gradually have now a decentralized, two-way power generation system.

The participation of customers can be fully optimized in the future if the currently existing conventional power grid is upgraded to be smart grid, supported by smart information technology and communication and measuring equipment. This smart grid will allow customers to do online monitoring on the hourly load condition and the hourly pricing, helping them to determine the most favorable time to supply their power to PLN grid, besides detecting the power quality, using pre-paid fees, or even sending warning signs in the event of faults.

\section{REFERENCES}

[1] Schuitema G., Lisa Ryan, Claudia Aravena, "The Consumer's Role in Flexible Energy Systems: An Interdisciplinary Approach to Changing Consumers' Behavior", IEEE Power \& Energy for Electric Power Professionals, Vol.15, Number 1, January/February 2017. 
[2] Richter A., E. van der Laan, W. Ketter, K. Valogianni, Transitioning from the Tradisional to the Smart Grid: Lessons Learned from ClosedLoop Supply Chains, Rotterdam School of Management, Erasmus University Rotterdam, Netherlands.

[3] RUPTL PLN (Power Supply Business Plan of the National Electricity Company) 2016-2025.

[4] Regulation of Minister of Energy and Mineral Resources No. 31/2014.

[5] Soebagio A, "Tanggapan Atas Rencana Penyusunan Peta Jalan bagi Riset dan Pengembangan Teknologi Nuklir di Indonesia." (Comments on the Plan to Develop a Road Map for Research and Development of Nuclear Technology in Indonesia). Diskusi Nasional: Go Nuclear: Menantikan Kehadiran Reaktor Fusi di Indonesia (National Discussion on Go Nuclear: Waiting for the Arrival of Fusion Reactor in Indonesia), Universitas Kristen Indonesia, 1 December 2016.

[6] US Solar Power Growth through 2040: Exponential or inconsequential, Deloitte Center for Energy Solutions, September 2015.
Atmonobudi Soebagio received his Engineer in Electrical Engineering in 1977 from Universitas Kristen Indonesia, Jakarta. His Master and $\mathrm{PhD}$ degree in Electrical Engineering from University of Wisconsin at Milwaukee, USA, in 1988 and 1993, respectively. He is currently the Head of Center for Research and Policy Study of Renewable Energy Applications in Universitas Kristen Indonesia. He is also involved in research of renewable energy conversion, power quality, and energy policy for sustainable development.

Bambang Widodo received his Engineer degree in Electrical Engineering in 1987 from Universitas Kristen Indonesia. His Master's degree was received in 1997 from Universitas Indonesia. He is currently Head of the Department of Electrical Engineering in Universitas Kristen Indonesia. He is specialist in control engineering and power electronics equipment for supporting FACTS. 